\title{
A Convenor on Approval
}

\author{
By Alistair Gordon
}

The Approval Exercise in which psychiatric hospitals and units are approved for general professional training has recently completed the first round of visits to general psychiatric units. The present phase includes a continuing review of both fully and provisionally approved hospitals and first visits to subspecialty units in mental handicap, child and adolescent psychiatry, and forensic psychiatry. The announcement of an impending visit is likely to engender apprehension rather than a feeling of empathy with the task of the Convenor and his panel, but a description of the Convenor's role should dispel any misconception that it consists of a frolicsome succession of expense-accounted jaunts.

The Court of Electors appoints both a Convenor and a panel of about 30 potential visitors on the advice of each Division. The College's Approval Secretary provides each Convenor with a list of anticipated visits for the Division over each six-month period. These will include revisits to fully approved units after three years, annual revisits to provisionally approved units and inaugural visits to units newly included in the Approval Exercise. In most Divisions there will be about 20 hospitals or training schemes on the list each year. As visits are rarely welcomed during summer holiday months or the Christmas season, the Convenor will be involved in about two visits each month over the available visiting period. Several hospitals may be encompassed in a single visit if they lie in close proximity or are linked in rotational training programmes, but most panel members are too committed to spare more than two days away and the visiting programme must usually be tackled in small segments.

To inaugurate a visit, the Convenor must contact the Psychiatric Tutor and devise an appropriate programme for the visit so as to ensure that trainees and senior staff are available for interview. He must cajole or press-gang two visitors from the Division's panel to accompany him, make arrangements for their accommodation, contact the appropriate Professor of Psychiatry, the Postgraduate Dean of the Region, the College's representative on the Regional Postgraduate Committee (the 'Regional Adviser') and the representatives of the Health Authority involved-as well as arranging for his own absence from normal duties. These tasks are basically secretarial, but the exercise is a sensitive one, and personal contact is usually necessary to co-ordinate the visit effectiveiy. In practice, the most problematical part is the persuasion of panel visitors to provide their valued service.

The Convenor and the panel meet on the evening before the visit to discuss previous College and Joint Committee Approval reports and the comprehensive information submitted by the Psychiatric Tutor. A typical visit commences with an interview with the Tutor to elucidate the outline of the training programme and to ascertain the involvement of both trainees and consultant staff. The pivotal section of the visit is the interview with the trainees, which helps to clarify whether the aims of their training programme are realized effectively. Further interviews with consultant and nonmedical teaching staff assist in determining the validity of the comments of the trainee group and the feasibility of implementing any suggested modifications.

The panel's visit will include the postgraduate centre and library, probably some clinical areas, and often the staff accommodation for trainees. Since hospitals evolve such varied training programmes in conjunction with differing clinical opportunities, approval visits cannot follow a fixed pattern, but all visits certainly share a crowded, concentrated programme which leaves no leisure for touring the antiquities and scenic splendours of the locality.

The Convenor must be able to provide guidance to the panel about the scope, expectations and standards accepted by the College for Approval. He should be actively involved in postgraduate training if his adjudicatory role is to carry conviction. He requires, and will certainly develop, considerable diplomatic skills in order to contend with the understandable sensitivities of the hospital staff, to elicit deficits in training programmes without undermining morale, and to encourage realistic new programme developments without dogmatism. He will also benefit from possessing some hosting qualities to deal with the equal sensitivities of the visiting panel members if meals and accommodation fall below their expectations, as their services are essential to subsequent visits. The Convenor needs to become an adept map-reader in unfamiliar, often rural, localities-a lesson which I learned early after leading my irreplaceable panel members chassis-deep into a flood. An equable temperament helps to ride the shifting moods of the visit, as the initial smiles of welcome can change quickly to harried scowls, and departures can range from the receipt of bouquets to a swift dash for the nearest armoured escort.

At the conclusion of the visit, the Convenor assembles the panel's recommendations, presents a verbal report to the collective hospital staff, including the trainees, and must be prepared to respond to their enquiries or objections. After the visit, he prepares an extensive and detailed written report which is forwarded to the College for discussion at the Central Panel Meeting of all Convenors. These meetings, held every three months, involve a day of lively discussion between the Divisional Convenors and the Dean, during which each Convenor must present and defend, not always successfully, his panel's recommendations. This meeting is helpful in providing information for Convenors on stan- 
dards of training in all parts of Britain and Ireland. The amended reports are then considered by the Court of Electors before a final recommendation or Approval grading is made, which is then forwarded to the hospital or unit concerned with a report written jointly by the Convenor and Dean.

The role of the Convenor provides both himself and panel members with a valuable and informative insight into teaching and clinical practice in a wide range of psychiatric hospitals and units, considerable organizational experience, useful acquaintance with the procedure of College business, and a crash course in tactful relationships with colleagues. Despite the demands on time, the Convenors and their panel members will generally agree that involvement in the Approval Exercise is a worthwhile, enlightening and enjoyable experience.

\title{
Number Seventeen
}

\author{
By Alexander Walk
}

In my article 'Arrival in Belgrave Square' (News and Notes, June 1975), I promised that a future issue would contain a description of the College's new headquarters and of the way the house was being adapted for our use. It has taken over four years for the arrangement of the house to be sufficiently settled for the promise to be kept, and even now, as will be seen, further changes and developments are underway.

Number Seventeen is typical of the stuccoed postRegency mansions intended for a wealthy aristocratic clientele. The entrance has a classical portico and the front door is a decorative iron grille on frosted glass. The house has four floors, and a noble staircase ascends from the ground to the second floor. The ground and first floors, which contain what were the principal reception rooms, have service extensions towards the back of the house, connected by winding back stairs. The basement runs the whole length of the house and emerges nearly at ground level at the back. Here, in what one might call the garden, is a one-storey building which is the caretaker's fiat, and beyond a fence is a Mews House fronting Belgrave Mews West.

Entering the front hall the visitor will find the reception area and telephone switchboard by the foot of the main staircase. On the left is the ground floor reception area, which is capable of being used as a single hall or partitioned into two rooms. This may in the future constitute a Lecture or Meeting Hall holding about 120 people, but for the time being one room houses the College's first research project and the other some of the office staff.

The broad carpeted main staircase leads to the two principal 'state rooms'. Facing the square is the Council Chamber, where the decorative coloured wall panelling fortunately matches the furniture brought from Chandos House. Here the Council, Court of Electors and large Committees meet in comfort, and the spacious room has also been used, together with the adjoining Library, for receptions at the time of Annual Meetings.
The second room, allocated to the Library, is wellfurnished but is not yet fully operational. Before books could be brought up from their packing cases in the basement the floors of both this and the Council Chamber had to undergo extensive strengthening, and the final placing of books and journals must wait until further shelving has been provided.

The main staircase continues to the second floor, more conveniently reached by lift. Here at the front of the house is the President's room, elegantly furnished by generous donations during the Presidency of Professor Linford Rees; it is also used by the smaller Committees and for other small gatherings. Adjoining is the office of the College Secretary, Miss Natalie Cobbing. Further back is the general office, and that of the Assistant Secretary, Mrs Gail Lloyd, who has responsibility, among other things, for the affairs of the Divisions and Sections.

The third floor is reached by a more modest staircase or by the lift. Here is the Finance Department, served by $\mathbf{M r}$ Marsh and his staff. An adjoining office is occupied by Miss Jane Boyce and her assistant, who organize the work of some of the College's most important Committees (Public Policy, Education, Research, Manpower). Here also are the offices of the British Journal of Psychiatry, whose Editorial Secretary is Miss Jacqueline Yates, and of the College Bulletin, and that of the Services Manager, Mr King.

Down again and through a concealed door on the halflanding, and here we find departments created by the expanding activities of the College-the Examinations Office organized by Miss Jean Scudamore; the Approvals Office, where Mrs Jane Manley arranges the visitation of psychiatric hospitals and sees to the resulting reports; and the office of the Joint Committee on Higher Psychiatric Training, of which Mrs Carol Ross is the Administrative Secretary. By the back stairs or lift we return to the ground floor extension, which houses the basic needs of any sizeable organization. Mr J. L. Rodericks and Mr S. G. O'Malley look after membership matters both manually and 